\title{
COMPARISON BETWEEN MODEL ATMOSPHERES AND SPECTRA FROM EARLY-TYPE STARS
}

\author{
by E. H. AvretT and S. E. Strom \\ (Smithsonian Astrophysical Observatory \\ Harvard College Observatory \\ Cambridge, Massachusetts, U. S. A.)
}

RÉsumt. - Nous donnons les caractéristiques observables d'un ensemble de modèles d'atmosphère, non gris, en équilibre thermodynamique de température effective comprise entre $10000^{\circ} \mathrm{K}$ et $20000^{\circ} \mathrm{K}$ et de gravité à la surface comprise entre $10^{3}$ et $10^{4}$. Ces calculs ont été faits pour faciliter l'interprétation d'observations du continu dans l'ultraviolet. Pour trois de ces modèles, nous tenons compte des ailes des raies de l'hydrogène (Balmer et Lyman). Nous introduisons aussi, de façon approximative, d'autres effets du "blanketing " des raies dans l'ultraviolet. Enfin, nous donnons des résultats préliminaires de calculs effeclués pour tenir compte des écarts à l'ETL.

Pour vérifier la validité de ces modèles, on compare les prédictions théoriques du flux dans le continu et du profil des raies avec les observations de Véga et de Sirius.

Les désaccords entre la théorie et l'observation sont étudiés du point de vue de ces nouveaux calculs. On trouve un accord généralement bon av.c les observations récentes de T. STECHER.

A BSTRACT. - To assist in the interpretation of ultraviolet continuum observations, we present observational features of a grid of non-grey model atmospheres in strict radiative equilibrium which have effective temperatures in the range $10000^{\circ} \mathrm{K}$ to $20000^{\circ} \mathrm{K}$ and surface gravities $10^{3}$ and $10^{4}$. For three models, we add the blended wings of the higher Balmer and Lyman hydrogen lines and include in an approximate way further effects of line blanketing in the ultraviolet. Finally, we present a preliminary calculation of the effect of departures from L.T. E. on the continuous flux.

To examine the validity of the models, we compare the predicted continuous flux and predicted line profiles with the corresponding observed quantities for Vega and Sirius.

We consider the question of discrepancies between theory and observations in the ultraviolet from the viewpoint of these new calculations, and find generally good agreement with recent observations made by T. STEOHER.

Резюме. - Мы даем наблюдаемы характеристики совокупности атмосферных моделей, не сер ых в термодинамическом равновесии с эфффективной температурой заключенной между $10000 \kappa^{0}$ и $20000 \mathrm{k}^{0}$ и силой тяжести на поверхности заключенной между $10^{3}$ и $10^{4}$. Эти вычисления были сделаны, чтобы облегчить интерпретацию наблюдений континуума в ультрафиолетовой области. Для трех из этих моделей мы учитываем крылья линий водорода (Бальмера и Лаймана). Мы также вводим, приближенно, другие эфффекты явления «blanketing» линий в убьтрафиолетовой области. Наконец, мы приводим предварительные результаты. Вычислений, проведенных для учета отклонений в локальном термодинамическом равновесии.

Чтобы проверить годность этих моделей, сравнены теоретические предвидения потока в континууме и контура линий с наблюдениями Вега и Сириуса.

Разногласия между теорией и наблюдением рассмотрены с точки зрения этих новых вычислений найдено хорошее, в общем, согласие с недавними наблюдениями T. Stecher.

Model atmospheres are necessary for the interpretation of continuum observations, both in the visual and ultraviolet and for the calculation of theoretical line spectra. For many purposes it is necessary to have models that are in radiative equilibrium to a high degree of accuracy. Before the very recent calculations by MIHALAS (1964) and by STROM (1964), there has not been available a sufficiently complete grid of radiative equilibrium models including general sources of continuous opacity. With particular reference to the interpretation of ultraviolet continuum observations, we present some of the characteristics of a detailed grid of models in the effective temperature range $10,000 \mathrm{~K}$ to $20,000^{\circ}$ and with surface gravities $10^{3}$ and $10^{4} \mathrm{~cm} / \mathrm{s}^{2}$. Continuous opacity sources $\mathrm{H}$, $\mathrm{H}-, \mathrm{H}_{2}^{+}, \mathrm{He} \mathrm{I}, \mathrm{He}$ II, and the effects of electron and Rayleigh scattering are included. In the 
basic set of models that we first describe, all line opacities are omitted, and we assume local thermodynamio equilibrium.

Certain of these models have been compared in detail with similar ones calculated by GnvGHRIOH and by Mrinalas. These comparisons, and a number of internal checks, indicate that our calculated temperature and emergent flux values are accurate to a few percent or better.

In figure 1 we show the emergent flux per unit

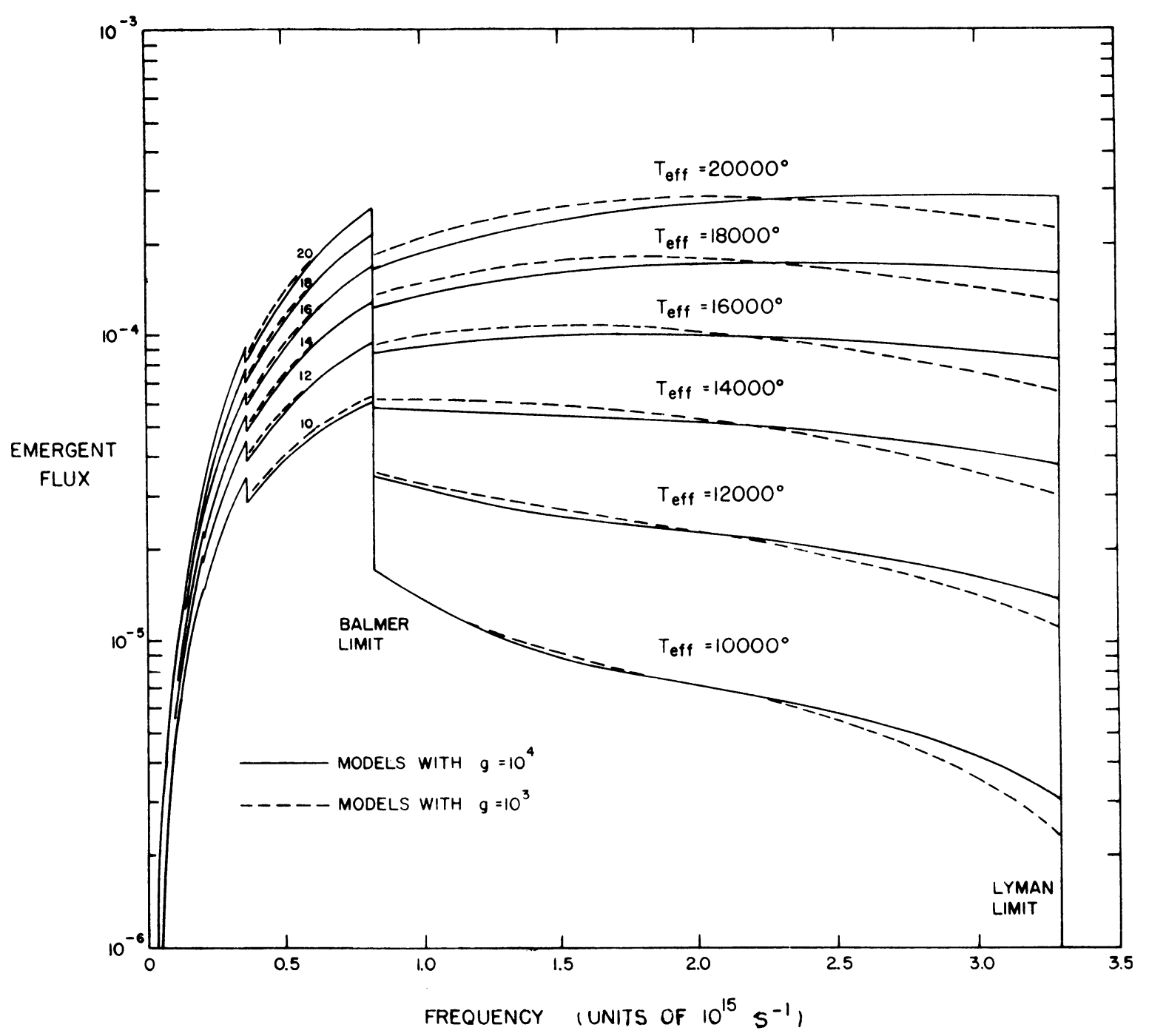

Fra. 1. - The emergent flux per unit frequency plotted against frequency for a grid of stellar models.

frequency for models with effective temperatures from $10,000^{\circ}$ to $20,000^{\circ}$ and two values of surface gravity. This figure illustrates the change in the Balmer discontinuity and the change in ultraviolet flux with effective temperature, and the effect of different surface gravities, particularly in the higher temperature models.

In these models the temperature distribution has been determined so that the integrated flux is constant with depth. Since models calculated with a grey temperature distribution have been widely used in the interpretation of stellar spectra it is useful to illustrate the range of errors in such calculations. In figure 2 we compare the emergent flux calculated by the two methods. Note the serious disagreement in the Balmer discontinuity and in the ultraviolet flux for the higher temperature models. In figure 3, the two temperature distributions are compared.

We have also compared our results with the 
radiative equilibrium models published by UNDERHIIL (1962). The basic difference between our calculations and those of Miss UNDERHIL is the inclusion of a more systematic temperature correction procedure (AVRETT and Kroor, 1963).
Values of the emergent monochromatic flux that we compute are in very close agreement with the corresponding UNDERHILL values. The only essential difference that we find is in the temperature distribution at small $\tau$, as shown in figure 4 .

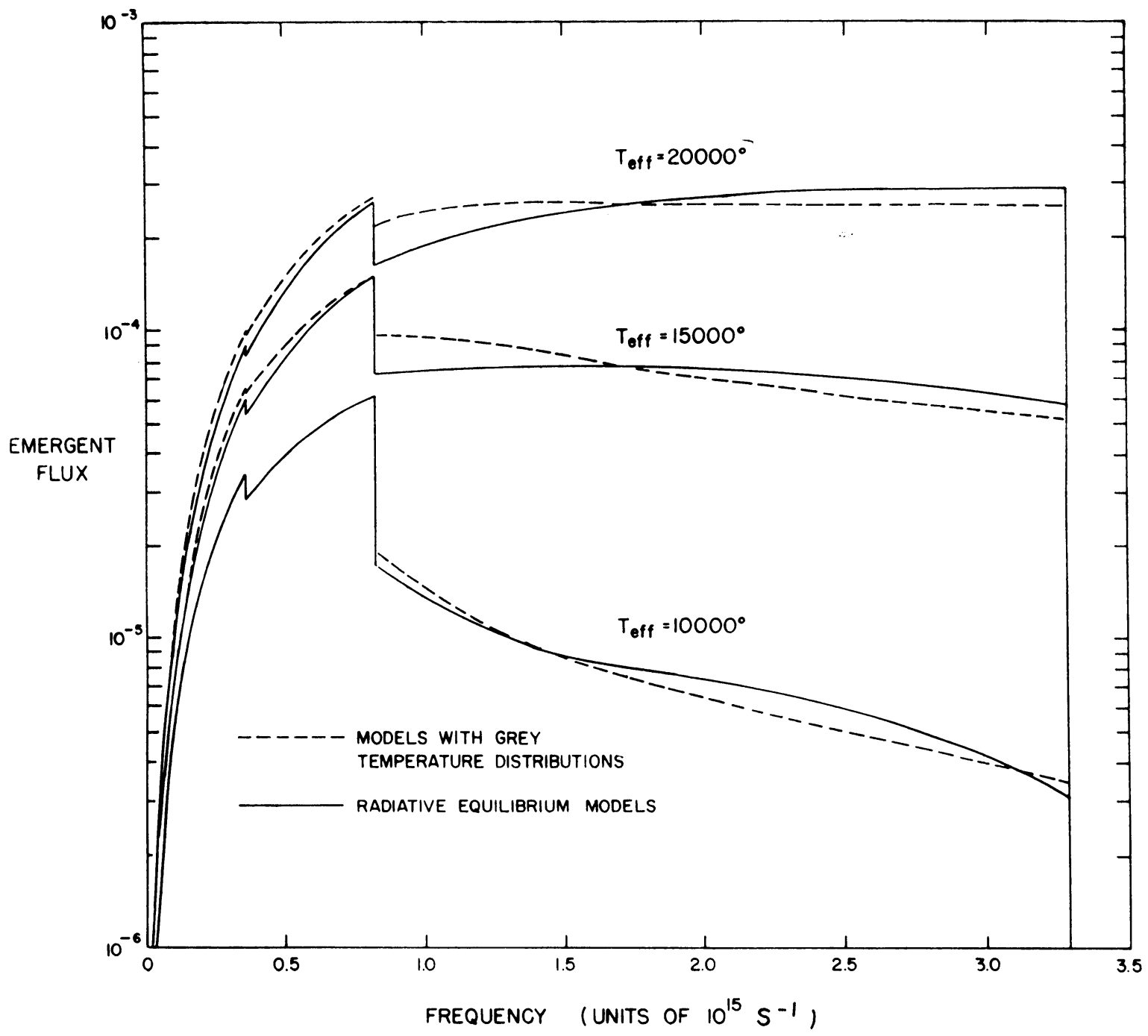

Fia. 2. - Comparison between the emergent fluxes calculated from grey and radiative equilibrium temperature distributions.

This difference arises from the greater accuracy we have obtained in satisfying the condition of radiative equilibrium in the outer layers. In each case, the temperatures are in good agreement in those regions where most of the continuous flux is formed. The differences are significant only in line calculations. We illustrate this point by calculating the line profile of Si II, $\lambda \lambda 4130$, from each of the two temperature distributions. In both calculations, $\mathrm{T}_{\text {eff }}=15333 \circ \mathrm{K}, g=10^{4}, \mathrm{X}$ (hydrogen abundance by number) $=0.9$. The parameters describing the formation of the line are identical. The two calculated profiles are compared in figure 5 . 
All of the models discussed so far neglect the effects of absorption lines on the continuous flux.

We now consider the effect of the blended wings of closely spaced lines and the influence of any substantial amount of flux removed from the spectrum by strong lines. Changes in temperature in those regions that do not influence the continuous flux will be disregarded in the following discussion.

The effect of the blended wings of the higher

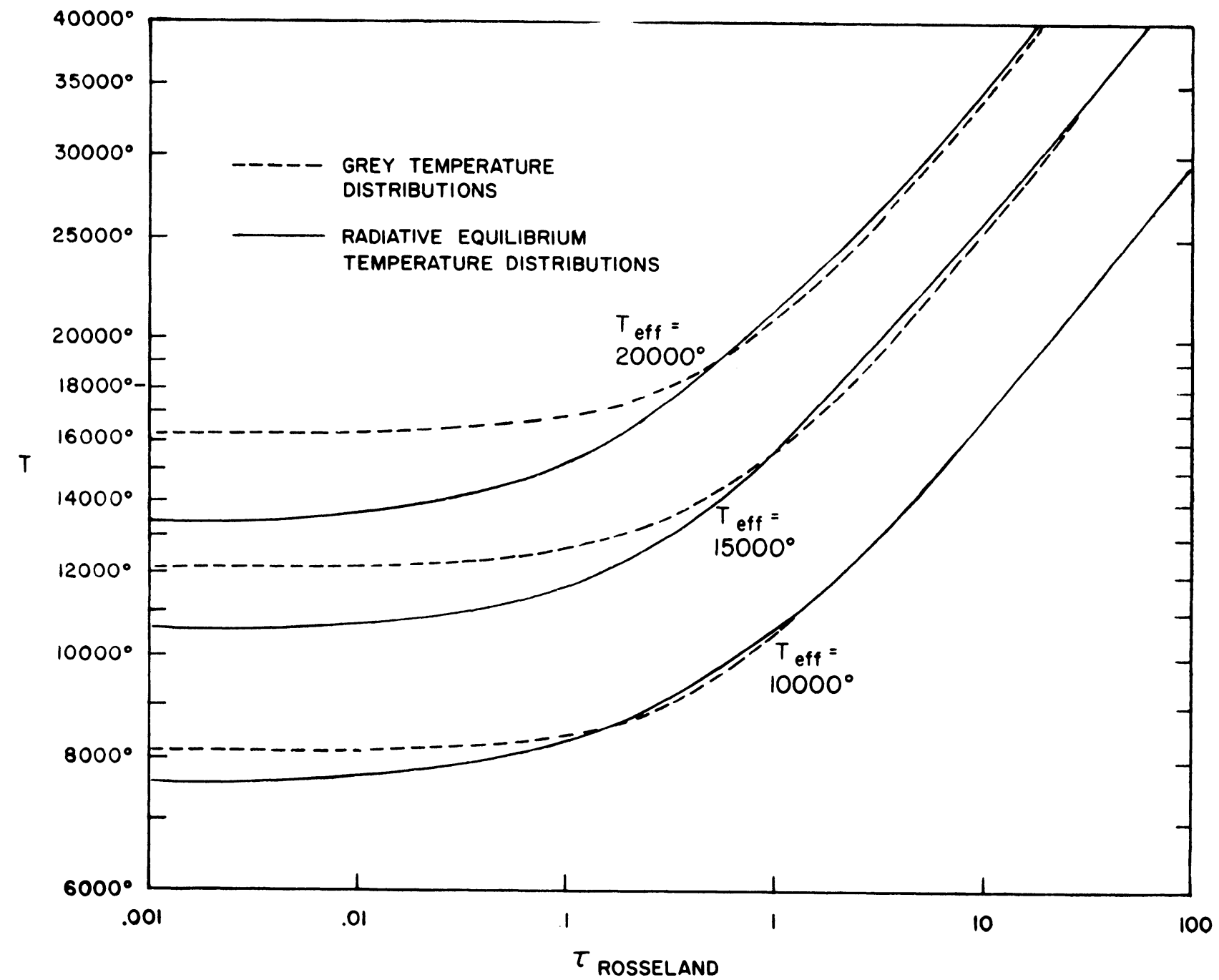

Fra. 3. - Comparison between the grey and radiative equilibrium temperature distributions.

Balmer and Lyman lines of hydrogen was calculated as follows. Using the Kolb-Griem theory, the combined opacity from Balmer lines higher than $\mathrm{H}_{\gamma}$ and Lyman lines higher than $\mathrm{L}_{\gamma}$ were calculated at frequencies half-way between line centers. A smooth fit to these values was then added to the continuous opacity in the calculation of a new radiative equilibrium model. The results are shown in figure 6 . Now the models show a continuous flux distribution near the Balmer limit in general accord with the observations. Also, there is a noticeable redistribution in the ultraviolet continuous flux and a change in the Balmer discontinuity, particularly in the higher temperature models. Since the area under the flux curve must remain the same for the same effective temperature, the flux removed by the higher opacity sources near the Balmer and particularly the Lyman limits must reappear at other frequenoies. 


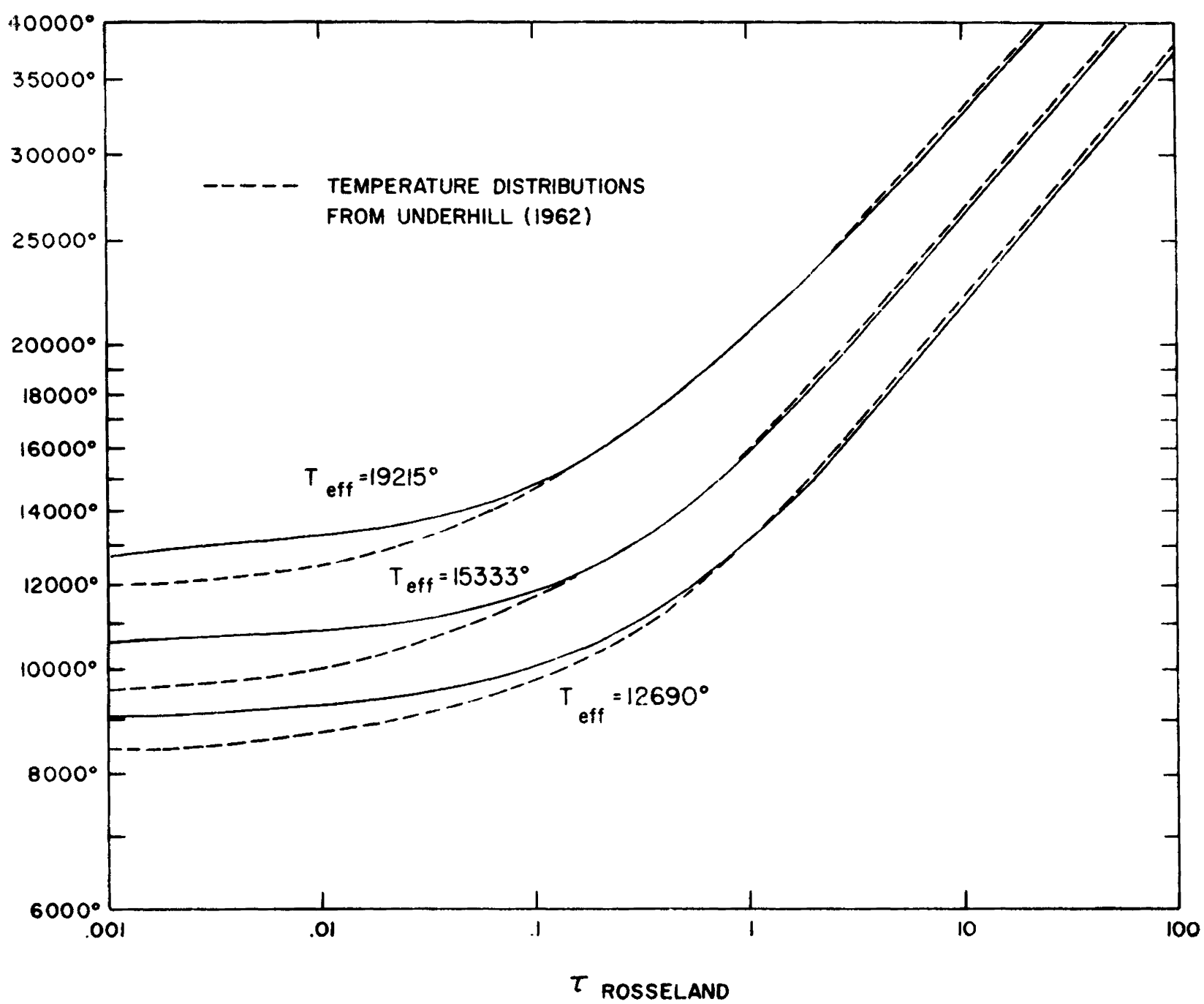

Fre. 4. - Comparison between the radiative equilibrium temperature distributions calculated by the authors and by Miss UNDERHIII (1962).

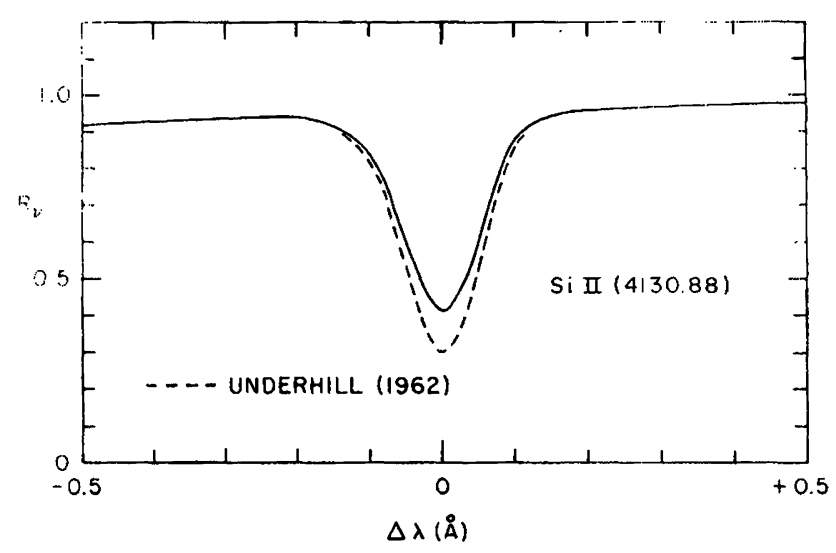

Fia. 5. - Comparison between a silicon line profile calculated by the authors and by Miss UNDERHILl for models with $\mathrm{T}_{\text {ell }}=1533{ }^{\circ} \mathrm{K}, \log g=4, \mathrm{X}=0.9$.
We now turn to the overall effect of strong individual lines. In figure 7 we show the equivalent widths of lines in the far ultraviolet calculated by GaUSTAD and SPITzer (1961) for a $20,000^{\circ}, P_{e}=2 \times 10^{3}$, Schuster-Schwartzschild model. In addition to hydrogen, the indicated lines correspond predominantly to transitions of N II, C II and III, and Si III. We have calculated new models with the flux assumed to be entirely removed in the frequency intervals shown at the bottom of this figure. We confine our attention to the redistribution of the continuous flux and ignore the resulting unrealistic temperature distribution at very small $\tau$. The results are given in figure 8 . The flux is changed by a larger amount in the Balmor continuum than in the previous case. 
However, there appears to be no larger effect on the Balmer discontinuity. We feel that even this simplified calculation should give a more representative result than a calculation that includes detailed line profiles but does not include a recal- culation of the radiative equilibrium model. (For example, see MorTon, 1964.)

We finally consider, in a preliminary way, the effect of the L. T. E. assumption in these calculations. In collaboration with W. KALKOFEN (KAL-

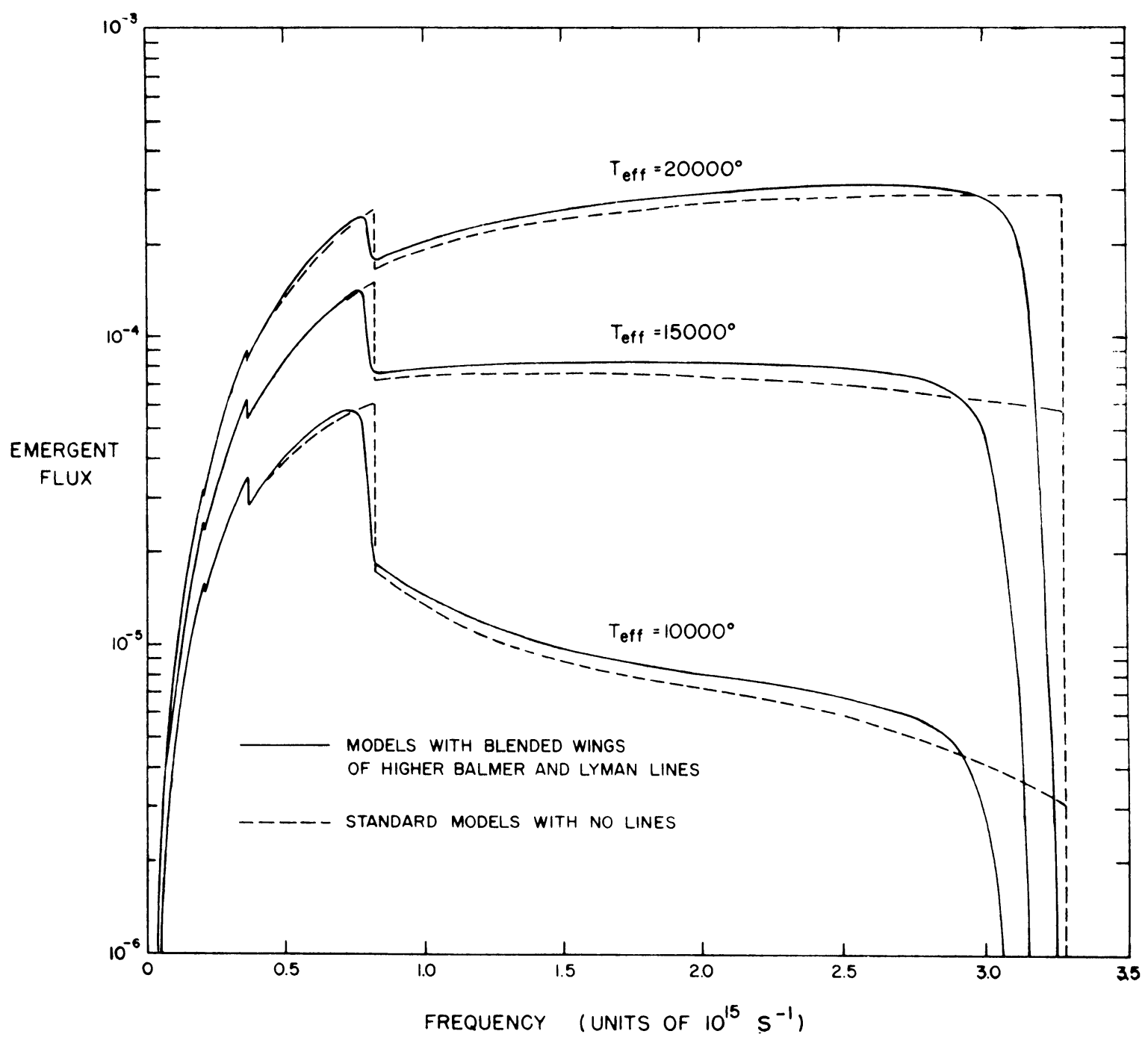

Fia. 6. - Comparison between the emergent fluxes calculated for models having only continuous sources of opacity and models including the blended wings of the higher Balmer and Lyman lines.

KOFEN, 1964, KaLkOFEN and AvRETT, 1964) we have calculated pure hydrogen models in which the bound populations were permitted to depart from the values given by the Saha-Boltzmann equation. A consistent solution was determined for the equation of transfer and the equations of statistical equilibrium, first including only the bound-free radiative and collisional rates, then adding the bound-bound rates for the two lowest levels. The calculated fluxes in the Balmer and
Paschen continua were about the same in the two cases. The results are shown for a $10,000 \mathrm{oK}$ model in figure 9, along with the L. T. E. flux distribution. It seems quite possible that the addition of further bound-bound rates in the equations of statistical equilibrium will not substantially change this result. The general tendency of the non-L. T. E. effect appears to be a reduction in the Balmer discontinuity.

In order to test the validity of our stellar atmos- 


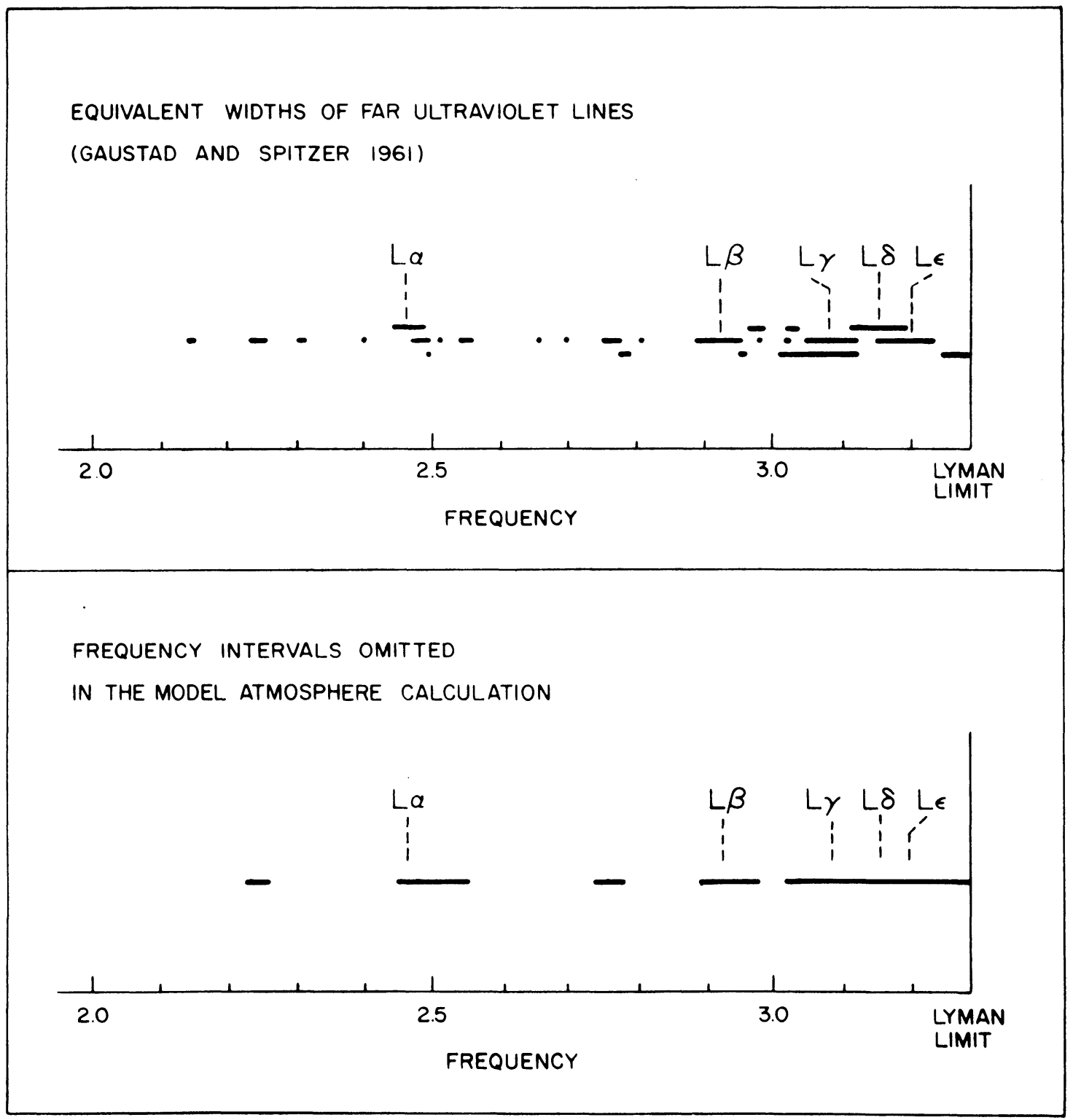

Fra. 7. - The equivalent widths of important ultraviolet lines on a frequency scale, and the frequency intervals omitted in the model atmosphere'calculations.

phere calculations, we compare the fluxes calculated for several models with those observed for $\alpha \operatorname{Lyr}(\mathrm{A} 0 \mathrm{~V})$ and $\alpha \mathrm{CMa}(\mathrm{Al} \mathrm{V})$. In figure 10, we plot, in addition to the observed flux for Vega, the emergent flux for two of these models

$$
\left(\mathrm{T}_{\text {eff }}=9500 \mathrm{o} \text { and } \mathrm{T}_{\text {eff }}=10^{4} \mathrm{oK}\right)
$$

in which we include the effects of the blended wings of the Balmer and Lyman lines. A model with $\mathrm{T}_{\text {eff }}=10000 \mathrm{oK}$ in which only continuous opacity sources are included, is displayed for comparison purposes.

On the basis of this comparison, we choose an effective temperature of 9500 oK for Vega.

This value of $T_{\text {eff }}$ is in excellent agreement with the value $9200 \pm 300 \circ \mathrm{K}$ deduced by HaNBURY Brown and his associates (1964) from their observations of Vega's radius. One should keep in mind, however, that the absolute calibration of the photometry may be in error by ten to twenty percent below $4000 \AA$. 
In figure 11, we compare an $\mathrm{H} \gamma$ profile calculated for a model in which $\mathrm{T}_{\text {eff }}=9500$ oK and $g=10^{3.8}$ with observations obtained photoelectrically by OKr at the Coude focus of the 100 inch telescope at Mt. Wilson. The agreement is good to about 1 percent except near the line core.
The effective temperature of Sirius has also been determined directly from radius measurements. For this star, $\mathrm{T}_{\text {eff }}=9350 \pm 300 \mathrm{oK}$. However, although classified as $\mathrm{Al} \mathrm{V}$ and having an effective temperature essentially identical to Vega's, Sirius has been measured by Lrluer (1964) and by

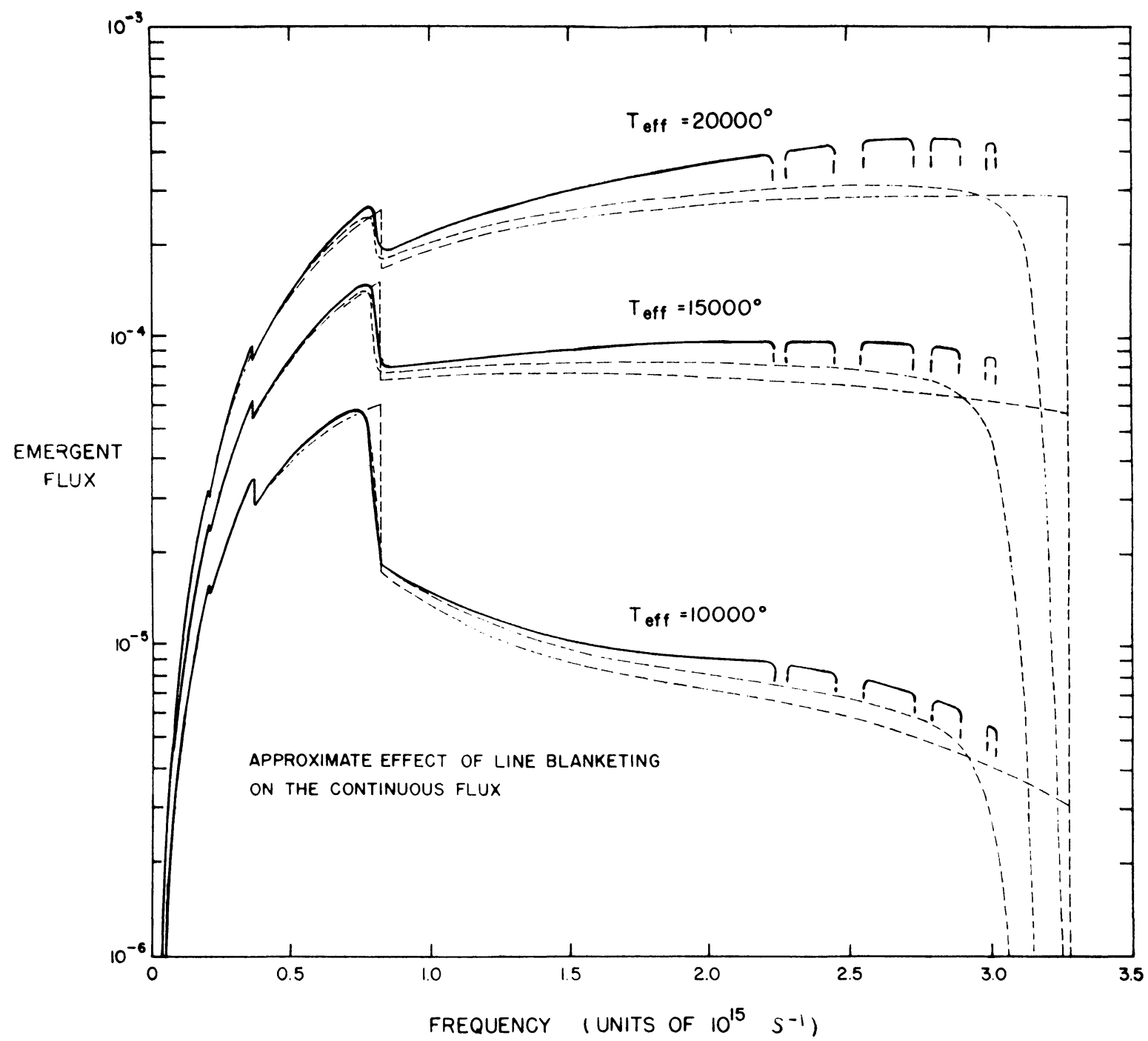

Fia. 8. - The approximate effect of line blanketing on the continuous flux for three representative models.

BLess (1964) to have a Balmer discontinuity about 0.10 magnitudes smaller than that measured for Vega. The existence of an abnormally small Balmer discontinuity is also reflected by the (U-B) color of -0.08 mag.

We speculate that a higher metal abundance is responsible for this effect. To support this hypothesis, we present in figure 12 , the monochromatic fluxes calculated by 0 . GINGERICH for three models for which $\mathrm{T}_{\mathrm{eff}}=9500 \mathrm{oK}, \log g=4.3$, $\mathrm{X}=.83, \mathrm{Y}=0.16$, and in which

$$
\log \mathrm{H} / \text { Metals }=2,3 \text { and } 4 .
$$

The major sources of metal opacity for these models are $\mathrm{Si}$ and $\mathrm{Mg}$. As the metal abundance is increased, the Balmer discontinuity is decreased as required by the observations. The effect of varying metal abundance appears critical in the 
choice of $T_{\text {eff }}$ at A0, although as one approaches earlier spectral types this effect becomes progressively less important. We and Dr. Gingarich hope, in the next few months, to complete a detailed abundance analysis of Sirius. This should settle the question of whether the disturbing difference between observations and models in this case can be explained by anomalous abundances.

As far as their validity is concerned, then, the model atmospheres are remarkably successful in

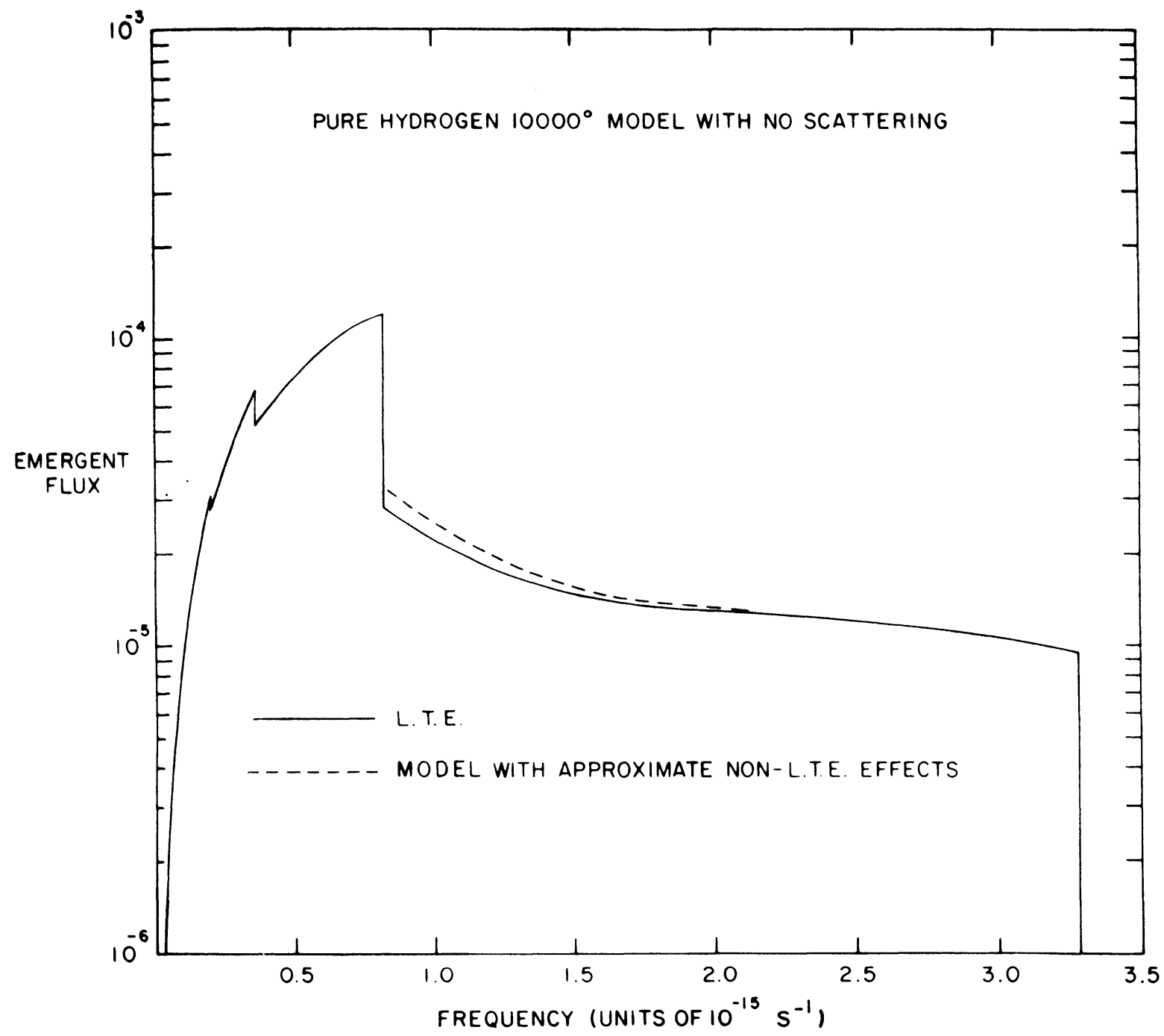

Fic. 9. - The approximate effect of departures from LTE on the emergent flux for a model having $\mathrm{T}_{\text {eff }}=10^{4} \mathrm{oK}, \log g=4.0, \mathrm{X}=1.00$.

predicting the monochromatic flux and $\mathrm{H}_{\gamma}$ profile for Vega and, by assuming a higher metal abundance, can reproduce the observed flux for Sirius.

In order to successfully compare observations made of the ultraviolet region of stellar spectra with model atmospheres, one requires either a direct tie-in with visual and near UV observations or an accurate scale of $\mathrm{T}_{\text {eft }}$ in terms of available observations in the visible. One of us (STRom) has attempted to establish such un effective temperature scale.

In order to readily compare our theoretical results with observations, we converted the calculated emergent flux values in the visual spectral region for each of our models into monochromatic magnitudes per unit wavelength relative to $5560 \AA$. 


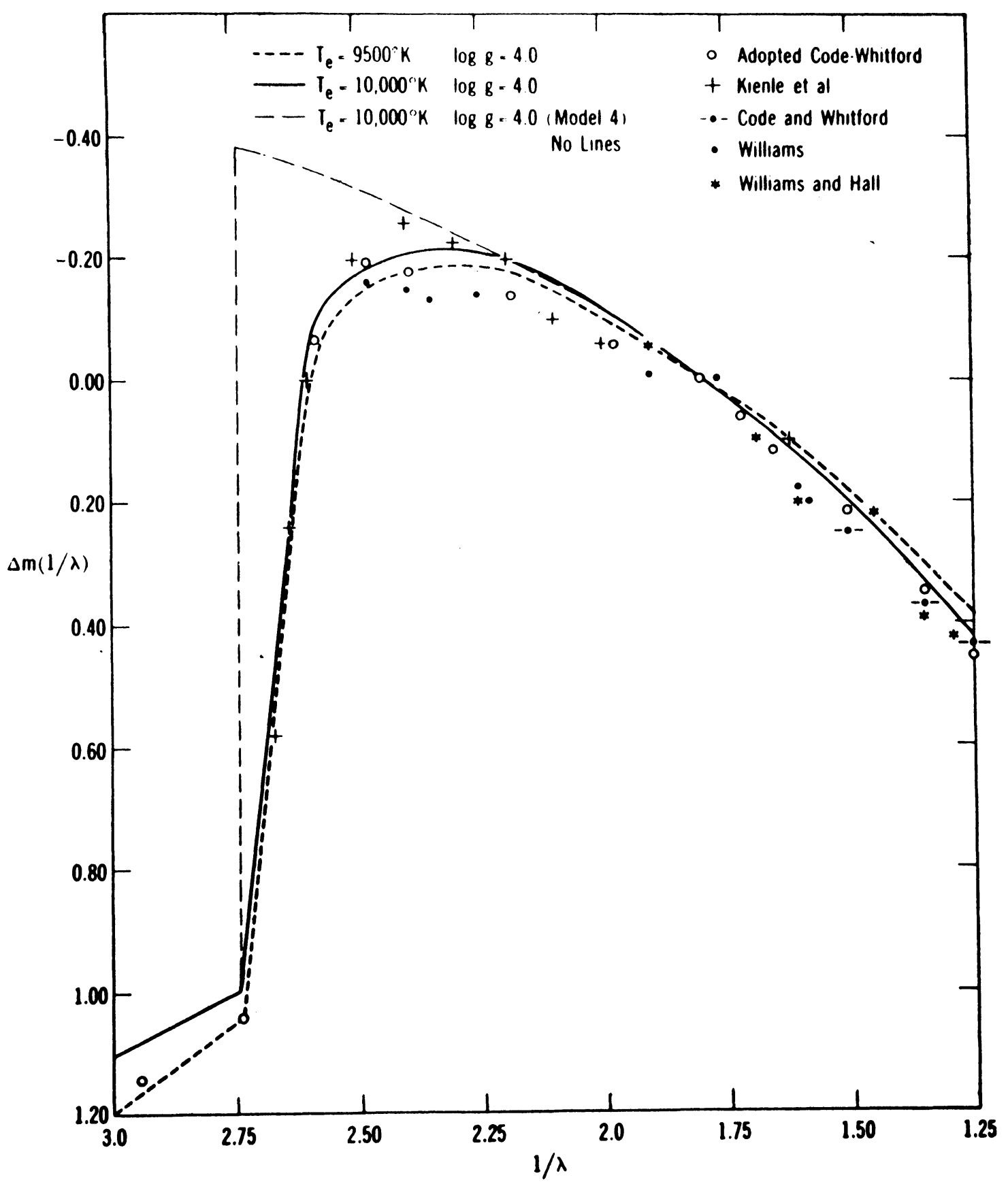

Fia. 10. - Comparison between monochromatic magnitude per unit frequency calculated for three model atmospheres and those observed for Vega.

The calculated monochromatic magnitude values for wavelengths shorter than the Balmer limit are extremely sensitive to temperature.

In figure 13, we compare the monochromatic magnitudes for two models with $\log g=4.0$, having $\mathrm{T}_{\text {eff }}=12,000 \mathrm{~K}$ and $13,000 \mathrm{oK}$. A temperature change of $1000 \mathrm{~K}$ results in a change of greater than 0.10 magnitudes in these ultraviolet colours.

The next figure compares the ultraviolet monochromatic magnitudes for models having the same $\mathrm{T}_{\text {eff }}$ of $12,000 \mathrm{oK}$ but different surface gravities, and shows a variation of less than 0.05 magnitude between the $\log g=3$ and $\log g=4$ models. 


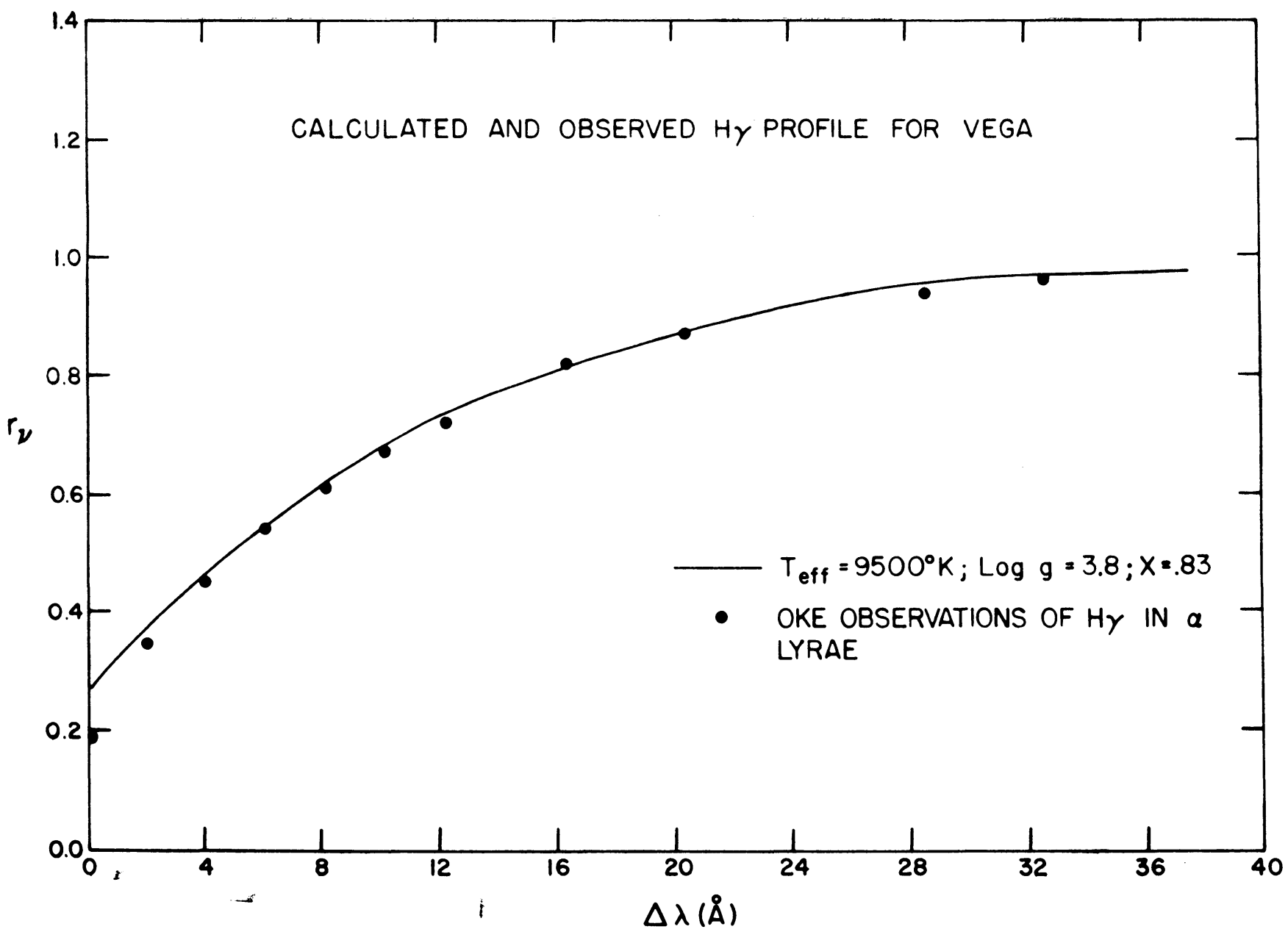

Fra. 11. - Compariann hetween observed and calculated $\mathrm{H}_{\gamma}$ profiles for Vega.

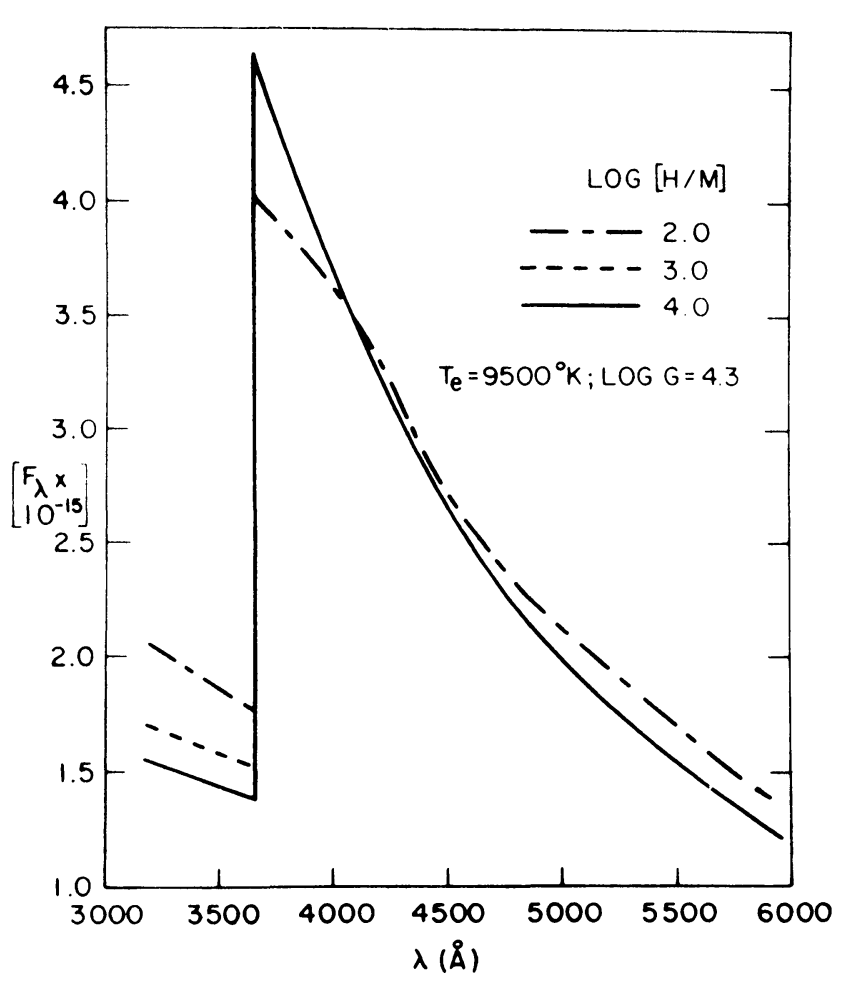

Fig. 12. - The effects of different metal abundances on the calculated emergent flux for a $10,000 \mathrm{~K}$ model.

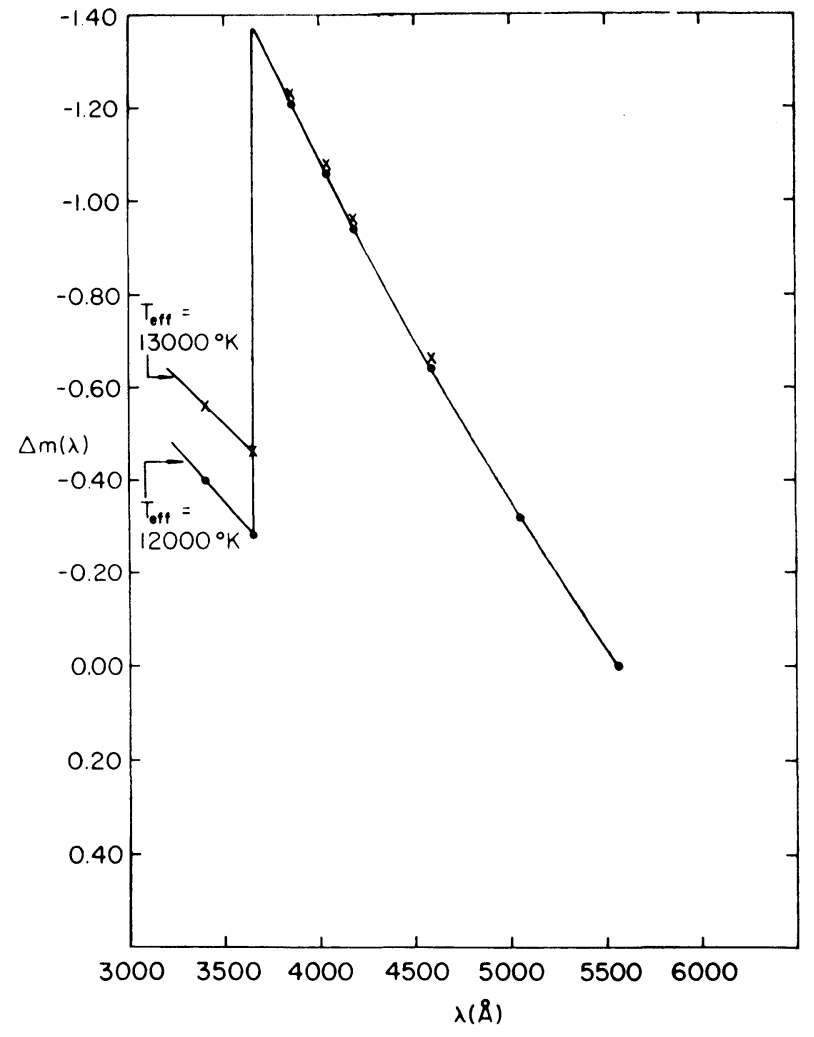

Fia. 13. - Calculated monochromatic magnitudes per unit wavelength relative to $5560 \AA$ for models with $\log g=4$, differing in $\mathrm{T}_{\text {eff }}$ by $1000 \mathrm{~K}$. 


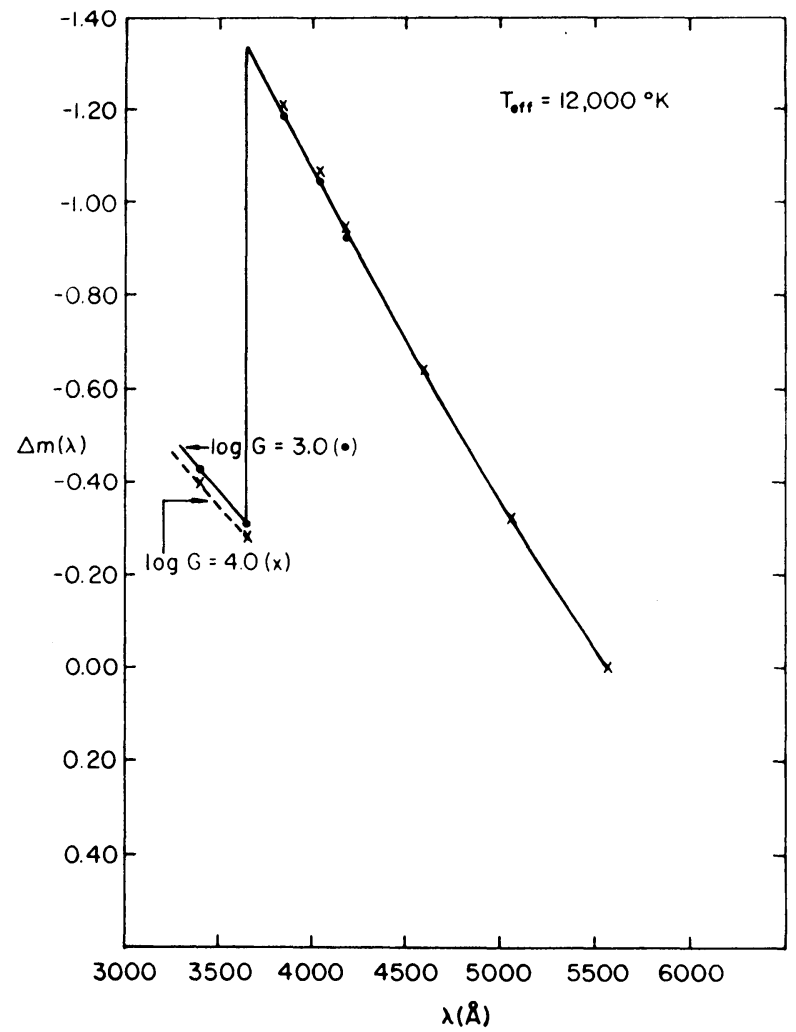

F1G. 14. - Calculated monochromatic magnitudes per unit wavelength relative to $5560 \AA$ for models with

$$
\mathrm{T}_{\text {eff }}=12000^{\circ} \mathrm{K}
$$

having $\log g=3$ and 4 .

Thus, if observations of stellar continuous fluxes at $3650 \AA$ and below are made to bette, $r$ than 0.05 magnitudes, we should be able to derive by comparison with the predicted flux from the models, values of the effective temperatures in the spectral region B0 through A0 to better than $500 \mathrm{oK}$. In figure 15, we plot for several ultraviolet wavelengths the theoretical values of the monochromatic magnitudes per unit wavelength, normalized to $5560 \AA$, against $\mathrm{T}_{\text {eft }}$ for our models for which $\log g=4.0$.

One of us (STrom) has observed a number of stars in the spectral range B5 through A0 with a spectrum scanner giving $25 \AA$ resolution. By means of the nomogram given in figure 15, we calculated for each program star an effective tem. perature which was the average of the $T_{\text {eff }}$ values determined for each of the four ultraviolet colours. A typical comparison between the models and observations is given in figure 16. In Table I we compare the scale of effective temperatures so derived with several previously published scales.

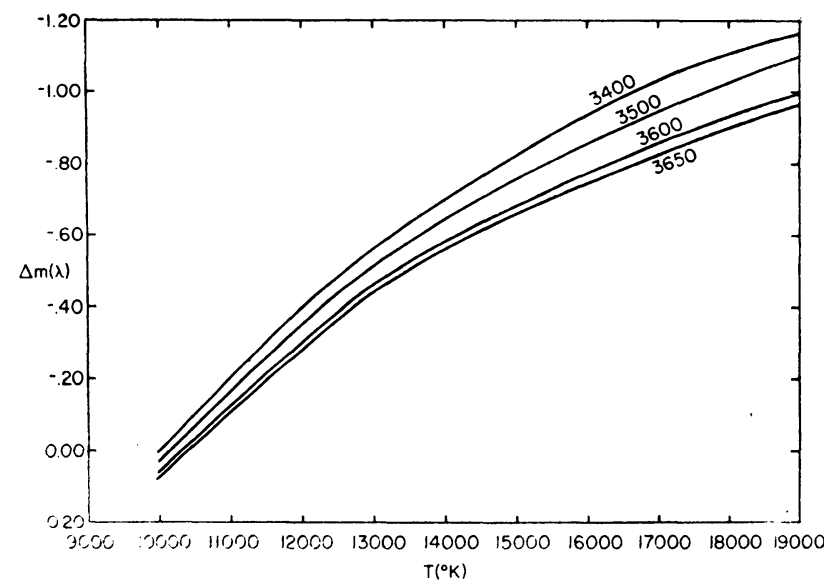

Fig. 15. - Theoretical values of the monochromatic magnitudes per unit wavelength, normalized to $5560 \AA$ plotted against $\mathrm{T}_{\mathrm{eff}}$ for models having $\log g=4$.

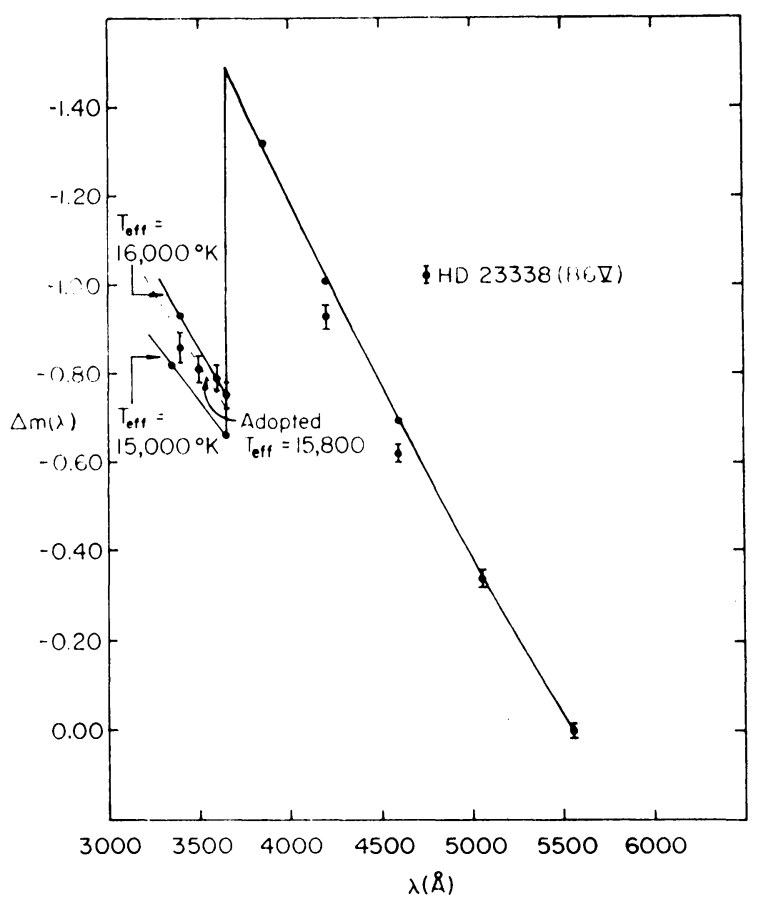

Fia. 16. - Observed monochromatic magnitudes per unit wavelength for HD 23338 compared with those predicted by two stellar models.

From the UBV colours obtained by JoHNsos, we plot in figure 17, the relation between unreddened (U-B) and $T_{\text {eff }}$.

For stars in the spectral region B6 through Al we plot in figure 18 the relation between spectral type and $\mathrm{T}_{\text {eff }}$. In addition to the program stars we include the direct determinations of $T_{\text {efs }}$ for $\alpha \mathrm{Lyr}, \alpha \mathrm{CMa}$ and $\beta$ Aur. We also include in the same plot, $T_{\text {eff }}$ determinations based on the spec- 


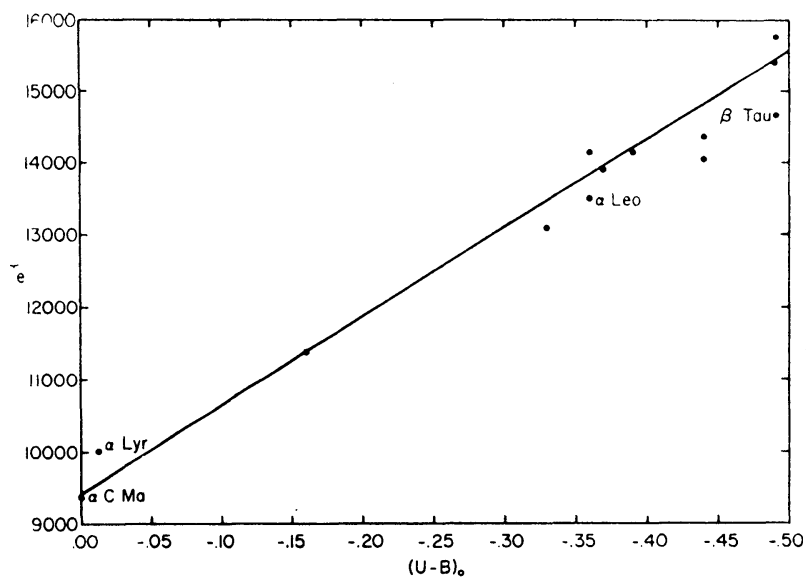

Fia. 17. - The relation between (U-B), and $T_{\text {eff }}$ deduced for a group of stars in the spectral-type range B5 through $\mathrm{AO}$

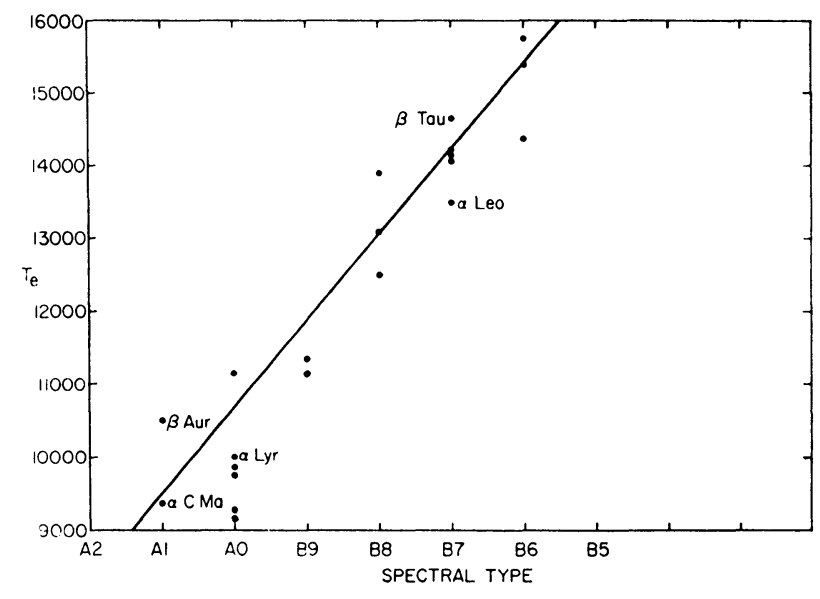

Fig. 18. - The relation between $\mathrm{T}_{\mathrm{eff}}$ and spectral type deduced by Strom.

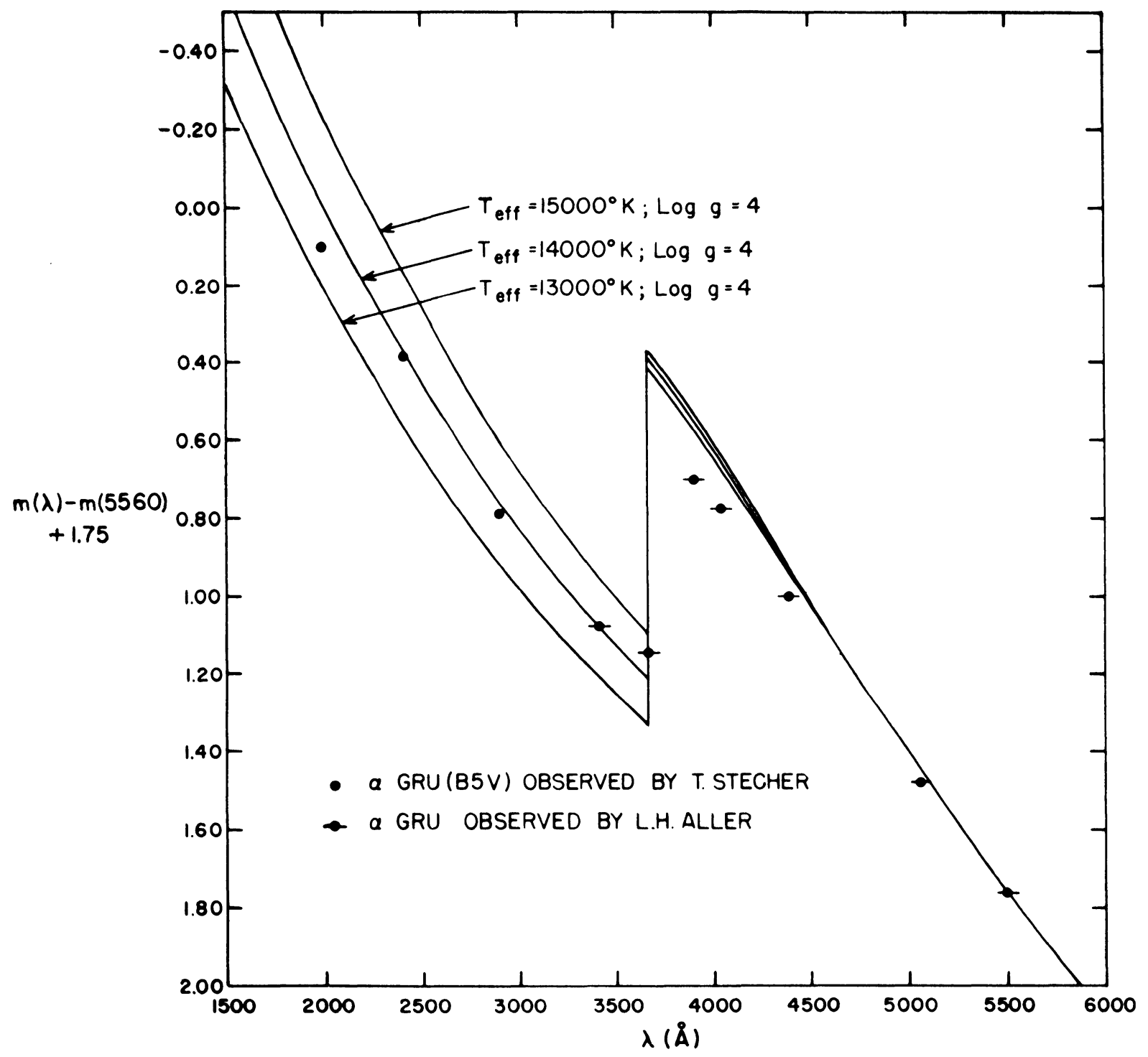

Fra. 19. - Comparison between monochromatic magnitudes per unit wavelength predicted from continuum models with observations of $\alpha$ Lyra. 
TABLE I

a Comparison of Various Scales of Effective Temperature

\begin{tabular}{|c|c|c|c|c|c|}
\hline \multicolumn{6}{|c|}{ Effective Temperature } \\
\hline & HARRIS & $\begin{array}{c}\text { KEENAN } \\
\text { AND } \\
\text { MoRGAN }\end{array}$ & KUIPER & $\begin{array}{l}\text { UNDERHILL, } \\
\text { POPPER }\end{array}$ & Strom \\
\hline & - & - & - & - & - \\
\hline$\ldots$. & 16,400 & 15,600 & 15,500 & - & - \\
\hline B6. & 15,400 & - & 14,500 & 15,333 & 15,600 \\
\hline B7 $\ldots \ldots \ldots$ & 14,500 & - & - & - & 14,200 \\
\hline B8 $\ldots \ldots \ldots$ & 13,400 & 12,800 & 12,300 & 12,690 & 13,500 \\
\hline B9 ....... & 12,400 & 11,800 & - & - & 11,250 \\
\hline $\mathrm{A} 0 \ldots \ldots \ldots$ & 10,800 & 11,000 & 10,700 & 9,400 & 9,750 \\
\hline
\end{tabular}

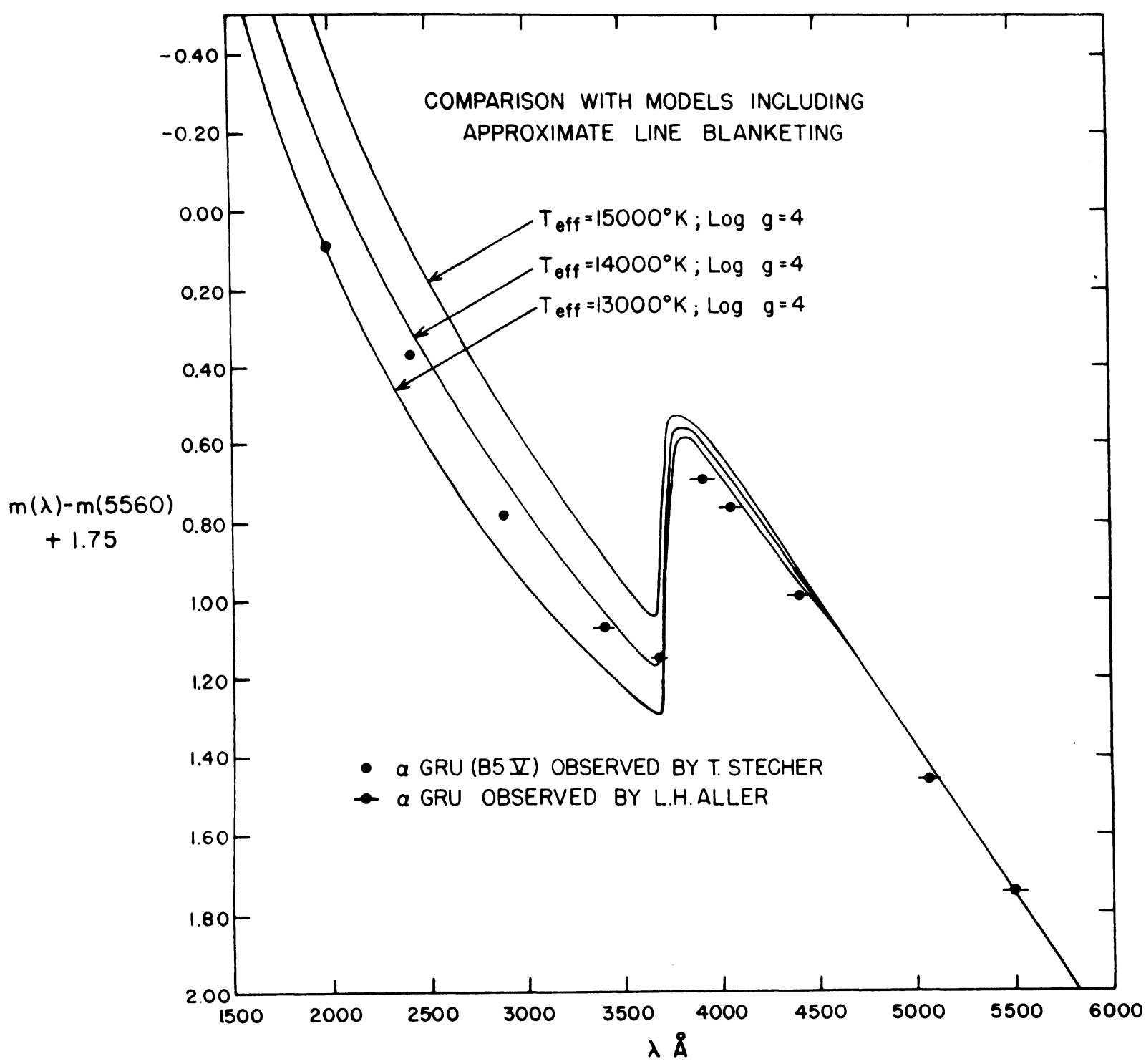

Fra. 20. - Comparison between monochromatic magnitude per unit wavelength predicted from models approximately including line - blanketing effects with observations of $\alpha$ Lyra. 
trophotometric observations of BLESs (1958) and OKE (1960).

Unfortunately, the difficulties involved in the calibration of Code and Whitford's primary spectrophotometric standard could introduce errors as high as 10-20 percent owing to poor absolute calibration of ultraviolet colours. The above uncertainty in the ultraviolet colours could lead to errors of $1000^{\circ}$ to $2000 \mathrm{oK}$ in the adopted value of the effective temperature. Discrepancies between various observers using the same primary standard also amounts to about 10 percent to 20 percent. In addition, these $T_{\text {eft }}$ values were based on comparison with models in which the effects of line blanketing were neglected. If line blanketing were included, the effective temperature soale would be lowered by between 500 to $1000 \mathrm{oK}$ for $\mathrm{T}_{\text {eft }}>15000$ oK̆.

In figure 19, we present a comparison between model atmospheres, which include only continuous opacity sources, and observations of $\alpha$ Gru (B5 V, $\mathrm{U}-\mathrm{B}=-.46$ ) both for the visual and UV.

The UV observations are preliminary in nature and were kindly supplied to us by T. STECHER in advance of publication. The visual and near UV colours were obtained by ALLER and his associates.

On the basis of the U-B color (see fig. 17), we would choose $T_{\text {eff }}=15,000 \quad 0 \mathrm{~K}$. This agrees fairly well with the value of $14,500 \mathrm{oK}$ one would derive by comparison with ArLER's measurements. STECHER's observations suggest that

$$
\mathrm{T}_{\text {eft }}=14,000 \mathrm{oK}
$$

best fits the ultraviolet observations.

In figure 20, we compare the same observations of $\alpha$ Gru with a set of models in which blanketing due to hydrogen and metallic lines has been included in an approximate way.

From these models, we could choose an effective temperature of about $14,000 \mathrm{oK}$ on the basis of the AluER observations and 13,500 oK from the ultraviolet flux determinations.

In view of these particular observations, we feel that the range of absolute and systematic errors in the photometry both in the visual and near ultraviolet and the range of possible choices of $T_{\text {eft }}$ from the models are such that there is now no large inexplicable discrepancy in the ultraviolet between theory and observation.

\section{Manuscrit reçu le 22 août 1964.}

\section{REFERENCES}

Avrett E. H. and Krook M., 1963, $A p . J ., 137,874$. Bless R. C., 1958, Thesis, University of Michigan.

Bless R. C., 1964, Private Communication.

GaUstad J. E. and SPITZER L., 1961, Ap. J., 134, 771. HanbURy Brown R., 1964, Nature, 201, 1111.

KaLkofeN W., 1964, Smithsonian Special Report, $167,176$.

KALKOFEN W. and AvRETt E. H., 1964, Astronom. $J ., 69,546$.
LILLER W., 1964, Private Communication. Minalas D., 1965, $A p . J .141,564$.

Morton D. C., 1964, Ap. J., 139, 1383.

OKE J. B., 1960, Ap. J., 131, 358.

Strom S. E., 1964, Thesis, Harvard University.

Underhill A. B., 1962, Pub. Dom. Ap. Obs. Victoria, 11, No 23. 